\title{
A comparative study on nutritional knowledge and dietary behavior between Korean and Chinese postpartum women
}

\author{
Sohyun Kim¹, Heewon L Gray ${ }^{2}$, Jia Li', Haeryun Park' ${ }^{1}$, Youngmi Lee ${ }^{1}$ and Kyunghee Song ${ }^{15}$ \\ ${ }^{1}$ Department of Food and Nutrition, Myongji University, 116 Myongji-ro, Cheoin-gu, Yongin-si, Gyeonggi 17058, Korea \\ ${ }^{2}$ Department of Community and Family Health, University of South Florida 13201, Florida, USA
}

BACKGROUND/OBJECTIVES: Proper nutrition intake during pregnancy and lactation is very important to both mothers and babies. Pregnant women should maintain proper nutritional status to restore decreased physical strength due to pregnancy and childbirth and produce breastmilk for the growth and development of the baby. Recently, the number of Chinese people living in Korea has increased as the exchange between Korea and China becomes active. It is important to provide proper nutrition education for pregnant women of both countries considering cultural differences.

SUBJECTS/METHODS: The subjects of this study were postpartum women in Gyeonggi, South Korea and Jinhua, China. The subjects were 20-45 years old less than six months after childbirth. A survey, using self-administered questionnaires, was conducted from October 2018 to January 2019. For data analysis, 221 Korean postpartum women (KPW) and 221 Chinese postpartum women (CPW) questionnaires were used.

RESULTS: KPW had significantly higher nutritional knowledge score and dietary attitude score than CPW $(P<0.001)$. However, overall score for dietary habits was significantly higher in CPW compared to KPW $(P<0.001)$. In KPW, nutritional knowledge $(P<0.01)$ and dietary attitude $(P<0.001)$ had significantly positive correlations with dietary habits. The proportions of KPW and CPW who answered that they had experience of nutrition education were $28.5 \%$ and $80.1 \%(P<0.001)$. The score for dietary habits was lower as the hours for watching TV and using mobile phone became longer in postpartum women of both countries, with significant differences in KPW $(P<0.001)$ and CPW $(P<0.05)$. In KPW, the score for dietary habits in postpartum women with exercise experience was significantly higher than that in postpartum women without exercise experience $(P<0.001)$. CONCLUSIONS: More pregnancy-related nutrition education should be provided and various and effective nutrition education programs, which not only transfer information but can be practiced in the actual life, should be developed.

Nutrition Research and Practice 2019;13(6):535-542; https://doi.org/10.4162/nrp.2019.13.6.535; pISSN 1976-1457 elSSN 2005-6168

Keywords: Nutritional knowledge, dietary behavior, postpartum women, Korea, China

\section{INTRODUCTION}

Proper nutrition intake during pregnancy and lactation is very important to both mothers and babies. Pregnant women should maintain proper nutritional status, restore decreased physical strength due to pregnancy and childbirth, and produce breastmilk for the growth and development of the baby.

Energy requirement for lactating women in Korea is higher compared to non-pregnant women of the same age, and the requirements for protein, dietary fiber, vitamin $A$, and watersoluble vitamins are also higher [1]. Still, the energy intake of Korean postpartum women within 3 months of childbirth has been insufficient, less than $80 \%$ of the recommended intake $[2,3]$. Also, the energy intake of Chinese postpartum women within 1 month of childbirth was lower than the level recommended by Chinese Dietary Guideline (2016) [4]. For proper and sufficient nutrition intake, desirable dietary habits should be accompanied; but it has been reported that dietary habits of
Korean postpartum women within 12 months of childbirth were worse than those of women with elementary school children [5]. Also, most postpartum women tend to practice improper weight management, namely by reducing the amount or the number of meals rather than by increasing exercise to control weights increased during pregnancy [6].

Even if postpartum women maintained desirable dietary habits before pregnancy, it is not easy for them to maintain such dietary habits after childbirth, because of the burden for postpartum care and infant care. Thus, proper energy intake and sufficient nutrient intake for postpartum women should be maintained through the establishment of desirable dietary habits and health-related lifestyle.

Recently, the number of Chinese people living in Korea has been increased as the exchange between Korea and China becomes active. According to the Statistics Korea, the number of Chinese people is about 530,000 taking the largest group among 1,170,000 foreigners living in Korea and the second

\footnotetext{
${ }^{\S}$ Corresponding Author: Kyunghee Song, Tel. 82-31-330-6206, Fax. 82-31-330-6200, Email. khsong@mju.ac.kr

Received: October 10, 2019, Revised: October 25, 2019, Accepted: October 31, 2019

This is an Open Access article distributed under the terms of the Creative Commons Attribution Non-Commercial License (http://creativecommons.org/licenses/by-nc/3.0/) which permits unrestricted non-commercial use, distribution, and reproduction in any medium, provided the original work is properly cited.
} 
largest group among married immigrants $[7,8]$. Like this, the number of Chinese people living in Korea is increasing and considered an important maternal population of Korea, which is facing low birth rate problems $[9,10]$. However, immigrant women have difficulties in childbirth-related health management [11].

Therefore, it is important to provide proper nutrition education for pregnant women of both countries considering cultural differences. In China, the length of hospital stays and postpartum care after childbirth is longer compared to Korea, and the rooming-in system is mostly practiced [12-14]. Also, Korean women traditionally have seaweed soup after childbirth, while Chinese women believe that the body is recharged by eating traditional stew with pork or chicken [15].

For proper nutrition education considering such cultural differences, it is necessary to study dietary behavior of pregnant women in both countries. However, despite various recent studies on dietary behavior of Chinese people living in Korea, studies on postpartum women are not sufficient.

Thus, the study was performed to compare nutritional knowledge, dietary attitude, and dietary habits of Korean and Chinese postpartum women, to understand the factors related to dietary habits, and to provide the direction of proper nutrition education considering distinct characteristics of each country. Furthermore, it will provide information about nutrition education for Chinese immigrant women in Korea.

\section{SUBJECTS AND METHODS}

\section{Subjects}

The subjects of this study were postpartum women in Gyeonggi, South Korea and Jinhua, China. The subjects were 20-45 years old less than six months after childbirth. A survey, using self-administered questionnaires, was conducted from October 2018 to January 2019. Totally, 238 Korean postpartum women (KPW) and 246 Chinese postpartum women (CPW) were included. For data analysis, questionnaires of incomplete data were excluded and $221 \mathrm{KPW}$ and $221 \mathrm{CPW}$ questionnaires were used. This study was approved by the institutional review board of Myongji University, South Korea (No. MJU-2018-10-001-02).

\section{Study content}

The questionnaires were distributed in outpatient facilities or local hospitals and postpartum women wrote the answers directly. The questions were about general characteristics, anthropometric data, nutrition education and knowledge, dietary attitude, dietary habits, and health-related lifestyles.

General characteristics and anthropometric data consisted of age, height, pre-pregnancy weight, education level, monthly household income of the family, and the number of babies. Body mass index (BMI) was calculated from the height and pre-pregnancy weight. According to the 2000 Asia-Pacific Perspective, the BMl was classified into underweight $(\mathrm{BMl}<18.5$ $\mathrm{kg} / \mathrm{m}^{2}$ ), normal weight (BMl $18.5-22.9 \mathrm{~kg} / \mathrm{m}^{2}$ ) and overweight $\left(B M I \geq 23 \mathrm{~kg} / \mathrm{m}^{2}\right)$ [16].

Needs for nutrition education was scored by the Likert 5-point scale: "strongly disagree" 1 point, "disagree" 2 points, "so-so" 3 points, "agree" 4 points, "strongly agree" 5 points. Experience of nutrition education and sources of nutrition information were also evaluated. Nutritional knowledge consisted of 15 questions, including general nutritional knowledge and pregnancy nutritional knowledge. Each question was answered with "yes" or "no", and 1 point was given for correct answer and 0 point for incorrect answer. The perfect score of nutritional knowledge was 15 points.

The dietary attitude was assessed for 10 questions and scored by the Likert 5-point scale: "strongly disagree" 1 point, "disagree" 2 points, "so-so" 3 points, "agree" 4 points, "strongly agree" 5 points. After reverse coding of negatively worded questions, the average of total points was used for dietary attitude score; the higher the score, the better the dietary attitude.

The dietary habits consisted of 10 questions, including breakfast, adequate amount of food, combination of food groups, green and orange vegetables, fruits, vegetables, protein foods, dairy products, laver and kelp and oil-cooked food. Each question was scored by the Likert 5-point scale: "strongly disagree" 1 point, "disagree" 2 points, "so-so" 3 points, "agree" 4 points, "strongly agree" 5 points.

Watching TV and using mobile phone, and experience of exercise were also evaluated and used for health-related lifestyles factors.

\section{Statistical analysis}

Data on 221 KPW and 221 CPW were analyzed using SPSS (Statistical Package for the Social Science) WIN 25.0 program. Mean and standard deviation were calculated for nutritional knowledge, dietary attitude, dietary habits, and score of needs for nutrition education and the differences between KPW and CPW were evaluated for statistical significance using t-test. Differences in frequency in general characteristics and experience of nutrition education and source of nutrition education and lifestyle were analyzed using $x^{2}$ (Chi-square) test. Duncan's multiple range test was used to compare dietary habits and education level, watching TV and using mobile phone. Correlations between nutritional knowledge, dietary attitude and dietary habits were determined using Pearson's Correlation coefficient.

\section{RESULTS}

General characteristics and anthropometric data of subjects by country

The general characteristics and anthropometric data of KPW and CPW are shown in Table 1.

As for age, the percentage of CPW who were 26-30 years old (49.8\%) was higher than the percentage of KPW with the same age range $(36.7 \%)$, and the percentage of KPW who were 31-35 years old (36.2\%) was higher than the percentage of CPW with the same age range $(26.7 \%)$, respectively $\left(X^{2}=14.62, P<\right.$ 0.01). As for education level, the percentage of KPW who graduated from college $(80.1 \%)$ was higher than that of CPW (67.9\%), and the percentages of CPW who graduated from high school (22.2\%) and graduate school (10.0\%) were higher than those of KPW who graduated from high school (12.2\%) and graduate school $(7.7 \%)$, respectively $\left(X^{2}=9.239, P<0.05\right)$. As for 
Table 1. General characteristics and anthropometric data of subjects by country

\begin{tabular}{|c|c|c|c|c|c|c|}
\hline \multicolumn{2}{|c|}{ Classification } & \multirow{2}{*}{$\begin{array}{l}\text { Korea } \\
13(5.9)^{1)}\end{array}$} & \multirow{2}{*}{$\begin{array}{l}\text { China } \\
23(10.4)\end{array}$} & \multirow{2}{*}{$\begin{array}{c}\text { Total } \\
36(8.1)\end{array}$} & \multirow{2}{*}{$\begin{array}{l}t \text { or } x^{2} \\
14.62^{\left.* *^{2}\right)}\end{array}$} & \multirow{2}{*}{$\begin{array}{c}P \\
0.002\end{array}$} \\
\hline Age (yrs) & $\leq 25$ & & & & & \\
\hline & $26-30$ & $81(36.7)$ & $110(49.8)$ & $191(43.2)$ & & \\
\hline & $31-35$ & $80(36.2)$ & $59(26.7)$ & 139 (31.4) & & \\
\hline & $\geq 36$ & $47(21.3)$ & $29(13.1)$ & 76 (17.2) & & \\
\hline \multirow[t]{3}{*}{ Education level } & $\leq$ High school & $27(12.2)$ & $49(22.2)$ & $76(17.2)$ & $9.239^{*}$ & 0.010 \\
\hline & College & $177(80.1)$ & $150(67.9)$ & $327(74.0)$ & & \\
\hline & $\geq$ Graduate school & $17(7.7)$ & $22(10.0)$ & $39(8.8)$ & & \\
\hline \multirow{6}{*}{$\begin{array}{l}\text { Monthly household income } \\
(10,000 \text { won/yuan })\end{array}$} & $<300 /<8,000$ & $31(14.0)$ & $5(2.23)$ & $36(8.14)$ & $106.06^{* * *}$ & 0.000 \\
\hline & $300-399 / 8,000-9,999$ & $61(27.6)$ & $11(5.0)$ & $72(16.3)$ & & \\
\hline & $400-499 / 10,000-11,999$ & $45(20.4)$ & $27(12.2)$ & $72(16.3)$ & & \\
\hline & 500-599/12,000-13, 999 & $36(16.3)$ & $34(15.4)$ & $70(15.8)$ & & \\
\hline & 600-699/14,000-15, 999 & $20(9.0)$ & $59(26.7)$ & 79 (17.9) & & \\
\hline & $\geq 700 / \geq 16,000$ & $28(12.7)$ & $85(38.5)$ & $113(25.6)$ & & \\
\hline \multirow[t]{2}{*}{ Number of babies } & 1 & $151(68.3)$ & $132(59.7)$ & $283(64.0)$ & 3.546 & 0.060 \\
\hline & $\geq 2$ & $70(31.7)$ & $89(40.3)$ & $159(36.0)$ & & \\
\hline Height $(\mathrm{cm})$ & & $161.97 \pm 4.52^{3)}$ & $162.13 \pm 4.16$ & $162.05 \pm 4.34$ & -0.39 & 0.965 \\
\hline Pre-pregnancy Weight (kg) & & $55.32 \pm 7.92$ & $53.53 \pm 5.90$ & $54.42 \pm 7.03$ & $2.69 * *$ & 0.007 \\
\hline \multirow[t]{4}{*}{$\mathrm{BMI}^{4)}\left(\mathrm{kg} / \mathrm{m}^{2}\right)$} & Underweight & $28(12.7)$ & $26(11.8)$ & $54(12.2)$ & $10.94^{* *}$ & 0.004 \\
\hline & Normal & $152(68.8)$ & $177(80.1)$ & $329(74.4)$ & & \\
\hline & Overweight & $41(18.6)$ & $18(8.1)$ & 59 (13.3) & & \\
\hline & BMI & $21.08 \pm 2.85$ & $20.34 \pm 1.88$ & $20.71 \pm 2.44$ & $3.24^{* *}$ & 0.001 \\
\hline Total & & $221(50.0)$ & $221(50.0)$ & $442(100.0)$ & & \\
\hline
\end{tabular}

monthly household income, $27.6 \%$ of KPW families earned $3,000,000-4,000,000$ won and $38.5 \%$ of CPW families earned more than 16,000 yuan $\left(X^{2}=106.06, P<0.001\right)$. As for the number of babies, $68.3 \%$ of KPW and $59.7 \%$ of CPW have only one baby, but there was no significant difference. The average height of CPW $(162.13 \mathrm{~cm})$ was higher than that of KPW $(161.97 \mathrm{~cm})$, but there was no significant difference. As for the average of pre-pregnancy weight, KPW $(55.32 \mathrm{~kg})$ was heavier than CPW $(53.53 \mathrm{~kg})$ with a significant difference $(\mathrm{t}=2.69$, $P<0.01)$. As for BMI, the percentage of CPW who were in the normal range $(80.1 \%)$ was higher than KPW $(68.8 \%)$, and there were more KPW (18.6\%) than CPW $(8.1 \%)$ in the overweight range $\left(x^{2}=10.94, P<0.01\right)$.

Comparison of nutritional knowledge score of subjects by country Nutritional knowledge of KPW and CPW are shown in Table 2. Overall, KPW (12.36) had significantly higher scores than CPW (10.61, $P<0.001)$. Almost all KPW and CPW correctly answered the questions "Soft drink and cola don't contain calorie", "Calcium is the component of bones and teeth for mothers and babies", and "Breastfeeding increases uterine contraction". As for "Egg is a high cholesterol food", the rate of correct answers was significantly higher in CPW compared to KPW. But, the rate of correct answers to the questions "Nutrient requirements are all equal regardless of pregnant women and non-pregnant women" and "Formula milk contains more immune substances than breast milk" was not high in CPW.
Comparison of dietary attitude score of subjects by country Dietary attitudes of KPW and CPW are shown in Table 3. The average total score of dietary attitude in KPW (3.38) was significantly higher compared to CPW (3.10, $P<0.001)$. For KPW, the highest dietary attitude score was for "Dietary habits can be changed by circumstances or knowledge" (3.93), whereas the lowest score was for "Eating can solve problems due to boredom or anger" (2.61). For CPW, the highest dietary attitude score was for "Dietary habits can be changed by circumstances or knowledge" (3.63) like KPW, whereas the lowest score was for "When preparing a meal, I use whatever available without planning" (2.60).

Comparison of dietary habits score of subjects by country Dietary habits of KPW and CPW are shown in Table 4.

The overall score for dietary habits was significantly higher in CPW (3.40) compared to KPW (2.96, $P<0.001)$. Among 10 questions on dietary habits, three questions such as "Do you drink milk or eat other dairy products such as yogurt every day?", "Do you eat seaweed such as laver and kelp every day?" and "Do you eat oil-cooked food every day?" were not significant difference between two groups. Other 7 questions showed significantly higher scores in CPW compared to KPW $(P<0.001)$.

Comparison of nutrition education sources for pregnancy, experience and needs of subjects by country

Nutrition education for pregnancy in KPW and CPW is shown 
Table 2. Comparison of nutritional knowledge score of subjects by country

\begin{tabular}{|c|c|c|c|c|c|}
\hline Classification & $\begin{array}{c}\text { Korea } \\
(n=221)\end{array}$ & $\begin{array}{l}\text { China } \\
(n=221)\end{array}$ & $\begin{array}{c}\text { Total } \\
(n=442)\end{array}$ & $\mathrm{t}$ & $P$ \\
\hline High nutritional value food is high calorie food & $0.87 \pm 0.33^{1)}$ & $0.84 \pm 0.37$ & $0.86 \pm 0.35$ & 0.95 & 0.342 \\
\hline Protein is the component of muscle and blood & $0.87 \pm 0.33$ & $0.74 \pm 0.44$ & $0.81 \pm 0.40$ & $3.65^{* * 22}$ & 0.000 \\
\hline Soft drink and cola don't contain calorie & $0.96 \pm 0.20$ & $0.86 \pm 0.34$ & $0.91 \pm 0.28$ & $3.56^{* * *}$ & 0.000 \\
\hline Bean curd is a good protein food & $0.97 \pm 0.18$ & $0.73 \pm 0.45$ & $0.85 \pm 0.36$ & $7.44^{* * *}$ & 0.000 \\
\hline $\begin{array}{l}\text { Nutrient requirements are all equal regardless of pregnant women and } \\
\text { non-pregnant women }\end{array}$ & $0.83 \pm 0.38$ & $0.46 \pm 0.50$ & $0.64 \pm 0.48$ & $8.81^{* * *}$ & 0.000 \\
\hline Fat gives more energy than carbohydrate, protein & $0.54 \pm 0.50$ & $0.52 \pm 0.50$ & $0.53 \pm 0.50$ & 0.48 & 0.635 \\
\hline Egg is a high cholesterol food & $0.64 \pm 0.48$ & $0.77 \pm 0.42$ & $0.71 \pm 0.46$ & $-3.16^{* *}$ & 0.002 \\
\hline Carbohydrates can offer calorie & $0.94 \pm 0.24$ & $0.63 \pm 0.48$ & $0.78 \pm 0.41$ & $8.44^{* * *}$ & 0.000 \\
\hline High fiber food is good for protecting obesity & $0.94 \pm 0.24$ & $0.90 \pm 0.30$ & $0.92 \pm 0.27$ & 1.39 & 0.165 \\
\hline Calcium is the component of bones and teeth for mothers and babies & $0.97 \pm 0.18$ & $0.91 \pm 0.29$ & $0.94 \pm 0.24$ & $2.60^{*}$ & 0.010 \\
\hline Milk is good for preventing anemia in mothers & $0.45 \pm 0.50$ & $0.50 \pm 0.50$ & $0.48 \pm 0.50$ & -0.95 & 0.342 \\
\hline Formula milk contains more immune substances than breast milk & $0.84 \pm 0.37$ & $0.50 \pm 0.50$ & $0.67 \pm 0.47$ & $8.24^{* * *}$ & 0.000 \\
\hline The main carbohydrate of breast milk is lactose & $0.66 \pm 0.47$ & $0.59 \pm 0.49$ & $0.62 \pm 0.48$ & 1.57 & 0.117 \\
\hline Breastfeeding reduces breast milk production & $0.94 \pm 0.24$ & $0.79 \pm 0.41$ & $0.86 \pm 0.35$ & $4.65^{* * *}$ & 0.000 \\
\hline Breastfeeding increases uterine contraction & $0.95 \pm 0.23$ & $0.88 \pm 0.33$ & $0.91 \pm 0.28$ & $2.53^{*}$ & 0.012 \\
\hline Total score & $12.36 \pm 1.58$ & $10.61 \pm 1.75$ & $11.49 \pm 1.88$ & $11.06^{* *}$ & 0.000 \\
\hline
\end{tabular}

1) Mean $\pm \mathrm{SD}, 1$ point for correct answer or 0 point for incorrect answer

2) ${ }^{\star} P<0.05,{ }^{* *} P<0.01,{ }^{* \star *} P<0.001$

Table 3. Comparison of dietary attitude score of subjects by country

\begin{tabular}{|c|c|c|c|c|c|}
\hline Classification & $\begin{array}{c}\text { Korea } \\
(n=221)\end{array}$ & $\begin{array}{l}\text { China } \\
(n=221)\end{array}$ & $\begin{array}{c}\text { Total } \\
(n=442)\end{array}$ & $\mathrm{t}$ & $P$ \\
\hline I follow other's opinions when choosing foods or dishes. & $2.65 \pm 1.06^{1)}$ & $2.81 \pm 1.04$ & $2.73 \pm 1.05$ & -1.63 & 0.104 \\
\hline I don't try to taste foods that I dislike or similar foods & $2.99 \pm 1.20$ & $3.24 \pm 1.02$ & $3.12 \pm 1.12$ & $-2.39^{* 2)}$ & 0.017 \\
\hline Dietary habits can be changed by circumstances or knowledge & $3.93 \pm 0.92$ & $3.63 \pm 0.86$ & $3.78 \pm 0.90$ & $3.54 * * *$ & 0.000 \\
\hline Eating can solve problems due to boredom or anger & $2.61 \pm 1.19$ & $3.26 \pm 1.08$ & $2.93 \pm 1.18$ & $-6.00^{* * *}$ & 0.000 \\
\hline No reason to change the current diet as long as I am satisfied with it & $2.87 \pm 1.02$ & $3.19 \pm 1.07$ & $3.03 \pm 1.06$ & $-3.19^{* *}$ & 0.002 \\
\hline $\begin{array}{l}\text { I can change food habits form eating sweet snacks such as cookies and } \\
\text { candies to eating fruits and vegetables }\end{array}$ & $3.52 \pm 1.10$ & $3.26 \pm 1.01$ & $3.39 \pm 1.06$ & $2.61^{* *}$ & 0.009 \\
\hline I am willing to cook if I know how to cook foods into nutritious dishes & $3.90 \pm 1.03$ & $3.21 \pm 0.91$ & $3.55 \pm 1.03$ & $7.52^{* * *}$ & 0.000 \\
\hline I am trying to eat foods that I seldom had before, if they are good for health & $3.76 \pm 0.97$ & $3.33 \pm 0.90$ & $3.54 \pm 0.96$ & $4.76^{* * *}$ & 0.000 \\
\hline When preparing a meal, I use whatever available without planning & $3.15 \pm 1.11$ & $2.60 \pm 1.00$ & $2.88 \pm 1.09$ & $5.54^{* * *}$ & 0.000 \\
\hline I read food labels carefully when I purchase foods & $2.95 \pm 1.23$ & $2.70 \pm 0.91$ & $2.83 \pm 1.09$ & $2.42^{*}$ & 0.016 \\
\hline Total score & $3.38 \pm 0.47$ & $3.10 \pm 0.33$ & $3.24 \pm 0.43$ & $7.16^{* * *}$ & 0.000 \\
\hline
\end{tabular}

1) Mean $\pm \mathrm{SD}$, scored by a 5 -point Likert scale ( 1 = strongly disagree, 2 = disagree, $3=$ so-so, 4 = agree, $5=$ strongly agree)

2) $* P<0.05,{ }^{\star *} P<0.01,{ }^{\star * *} P<0.001$

Table 4. Comparison of dietary habits score of subjects by country

\begin{tabular}{|c|c|c|c|c|c|}
\hline Classification & $\begin{array}{c}\text { Korea } \\
(\mathrm{n}=221)\end{array}$ & $\begin{array}{l}\text { China } \\
(n=221)\end{array}$ & $\begin{array}{c}\text { Total } \\
(n=442)\end{array}$ & $\mathrm{t}$ & $P$ \\
\hline Do you eat breakfast every day? & $2.84 \pm 1.27^{1)}$ & $3.68 \pm 1.00$ & $3.26 \pm 1.22$ & $-7.80^{* * * 2)}$ & 0.000 \\
\hline Do you eat adequate amount of food for each meal? & $3.26 \pm 0.97$ & $3.71 \pm 1.08$ & $3.49 \pm 1.05$ & $-4.57^{* * *}$ & 0.000 \\
\hline Do you consider combination of food groups at each meal? & $2.58 \pm 1.02$ & $3.57 \pm 0.98$ & $3.08 \pm 1.12$ & $-10.35^{* * *}$ & 0.000 \\
\hline Do you eat green and orange vegetables every day? & $2.44 \pm 0.95$ & $3.08 \pm 0.97$ & $2.76 \pm 1.01$ & $-6.95^{* * *}$ & 0.000 \\
\hline Do you eat fruits every day? & $3.26 \pm 1.14$ & $3.74 \pm 0.90$ & $3.50 \pm 1.05$ & $-4.91 * * *$ & 0.000 \\
\hline Do you eat vegetables every day? & $3.18 \pm 1.08$ & $4.06 \pm 0.74$ & $3.62 \pm 1.03$ & $-9.98^{* * *}$ & 0.000 \\
\hline Do you eat meat, fish, egg or beans at least in 2 meals a day? & $3.19 \pm 1.01$ & $3.68 \pm 0.94$ & $3.44 \pm 1.01$ & $-5.26 * * *$ & 0.000 \\
\hline Do you drink milk or eat other dairy products such as yogurt every day? & $3.00 \pm 1.25$ & $2.81 \pm 1.04$ & $2.90 \pm 1.15$ & 1.82 & 0.069 \\
\hline Do you eat seaweed such as laver and kelp every day? & $2.71 \pm 1.06$ & $2.66 \pm 0.93$ & $2.69 \pm 1.00$ & 0.57 & 0.568 \\
\hline Do you eat oil-cooked food every day? & $3.16 \pm 0.85$ & $3.00 \pm 1.03$ & $3.08 \pm 0.95$ & 1.86 & 0.064 \\
\hline Total score & $2.96 \pm 0.63$ & $3.40 \pm 0.45$ & $3.18 \pm 0.59$ & $-8.28^{* * *}$ & 0.000 \\
\hline
\end{tabular}

1) Mean $\pm \mathrm{SD}$, scored by a 5 -point Likert scale ( 1 = strongly disagree, 2 = disagree, $3=$ so-so, 4 = agree, $5=$ strongly agree)

2) $* \star \star ~ P<0.001$ 
Table 5. Comparison of nutrition education sources, experience and needs of subjects by country

\begin{tabular}{|c|c|c|c|c|c|c|}
\hline \multicolumn{2}{|c|}{ Classification } & $\begin{array}{c}\text { Korea } \\
(n=221)\end{array}$ & $\begin{array}{c}\text { China } \\
(n=221)\end{array}$ & $\begin{array}{c}\text { Total } \\
(n=442)\end{array}$ & $t$ or $x^{2}$ & $P$ \\
\hline \multicolumn{2}{|c|}{ Score of needs for nutrition education } & $4.10 \pm 0.79^{1)}$ & $3.75 \pm 0.74$ & $3.93 \pm 0.78$ & $4.85^{* * * 2)}$ & 0.000 \\
\hline \multirow[t]{2}{*}{ Experience of nutrition education } & Yes & $63(28.5)^{3)}$ & $177(80.1)$ & $240(54.3)$ & $118.49^{* * *}$ & 0.000 \\
\hline & No & $158(71.5)$ & $44(19.9)$ & $202(45.7)$ & & \\
\hline \multirow{7}{*}{$\begin{array}{l}\text { Sources of nutrition information } \\
\text { (Multiple responses) }\end{array}$} & Doctor or dietitian & $74(16.7)$ & $156(35.3)$ & $230(25.9)$ & & \\
\hline & $\mathrm{TV}$ or radio & $21(4.8)$ & $8(1.8)$ & $29(3.3)$ & & \\
\hline & Internet or social network service & $184(41.6)$ & $200(45.2)$ & $384(43.3)$ & & \\
\hline & Acquaintance & $59(13.3)$ & $97(21.9)$ & $156(17.6)$ & & \\
\hline & Magazine & $36(8.1)$ & $43(9.7)$ & $79(8.9)$ & & \\
\hline & Others & $6(1.4)$ & $3(0.7)$ & $9(1.0)$ & & \\
\hline & Total & $380(42.8)$ & $507(57.2)$ & $887(100.0)$ & & \\
\hline
\end{tabular}

1) Mean $\pm \mathrm{SD}$, scored by a 5 -point Likert scale ( 1 = strongly disagree, 2 = disagree, $3=$ so-so, 4 = agree, $5=$ strongly agree)

2) $* \star * \quad P<0.001$

3) $\mathrm{N}(\%)$

Table 6. Dietary habits of KPW and CPW according to education, screen-viewing, exercise and nutrition education

\begin{tabular}{|c|c|c|c|c|c|c|c|c|c|}
\hline \multirow{2}{*}{\multicolumn{2}{|c|}{ Classification }} & \multicolumn{4}{|c|}{ Korea $(n=221)$} & \multicolumn{4}{|c|}{ China $(n=221)$} \\
\hline & & \multirow{2}{*}{$\frac{\mathrm{n}}{27}$} & \multirow{2}{*}{$\frac{\text { Mean } \pm \text { SD }}{2.90 \pm 0.48^{\mathrm{a} 1)}}$} & \multirow{2}{*}{$\frac{t \text { or } F}{3.69^{* 2)}}$} & \multirow{2}{*}{$\begin{array}{c}P \\
0.026\end{array}$} & \multirow{2}{*}{$\frac{n}{49}$} & \multirow{2}{*}{$\begin{array}{l}\text { Mean } \pm \text { SD } \\
3.31 \pm 0.52\end{array}$} & \multirow{2}{*}{$\begin{array}{l}t \text { or } F \\
2.24\end{array}$} & \multirow{2}{*}{$\frac{P}{0.109}$} \\
\hline Education level & $\leq$ High school & & & & & & & & \\
\hline & College & 177 & $2.94 \pm 0.64^{\mathrm{a}}$ & & & 150 & $3.41 \pm 0.42$ & & \\
\hline & $\geq$ Graduate school & 17 & $3.36 \pm 0.65^{b}$ & & & 22 & $3.55 \pm 0.50$ & & \\
\hline \multirow{3}{*}{$\begin{array}{l}\text { Watching TV and using mobile } \\
\text { phone (hrs/day) }\end{array}$} & $<2$ & 44 & $3.21 \pm 0.63^{a}$ & $8.268^{* * *}$ & 0.000 & 32 & $3.57 \pm 0.42^{\mathrm{a}}$ & $3.084^{*}$ & 0.048 \\
\hline & $2-4$ & 98 & $3.02 \pm 0.63^{\mathrm{a}}$ & & & 115 & $3.39 \pm 0.47^{b}$ & & \\
\hline & $\geq 4$ & 79 & $2.76 \pm 0.59^{b}$ & & & 74 & $3.33 \pm 0.42^{b}$ & & \\
\hline \multirow{2}{*}{$\begin{array}{l}\text { Exercise experience after } \\
\text { childbirth }\end{array}$} & Yes & 76 & $3.19 \pm 0.64$ & $-4.018^{* * *}$ & 0.000 & 187 & $3.41 \pm 0.43$ & -0.478 & 0.633 \\
\hline & No & 145 & $2.84 \pm 0.60$ & & & 34 & $3.36 \pm 0.59$ & & \\
\hline \multirow{2}{*}{$\begin{array}{l}\text { Experience of nutrition } \\
\text { education }\end{array}$} & Yes & 63 & $2.98 \pm 0.72$ & -0.217 & 0.829 & 177 & $3.43 \pm 0.44$ & $-2.228^{*}$ & 0.027 \\
\hline & No & 158 & $2.96 \pm 0.58$ & & & 44 & $3.26 \pm 0.48$ & & \\
\hline
\end{tabular}

1) a, b: Values with different superscripts are significantly different among groups by Duncan's multiple range test

2) $* P<0.05,{ }^{* * \star} P<0.001$

in Table 5.

The average score of needs for nutrition education in KPW (4.10) was significantly higher compared to CPW $(3.75, P<$ 0.001). The proportions of KPW and CPW who answered that they had experience of nutrition education were $28.5 \%$ and $80.1 \%$, respectively $(P<0.001)$. Analyzing multiple responses regarding sources of nutrition information revealed $41.6 \%$ of KPW and $45.2 \%$ of CPW chose internet or social network service and $16.7 \%$ of KPW and $35.3 \%$ of CPW chose doctor or dietitian.

Dietary habits of KPW and CPW according to education, screen-viewing, exercise and nutrition education

Dietary habits of KPW and CPW according to education, screen-viewing, exercise and nutrition education are shown in Table 6.

The score for dietary habits was higher as the education level became higher in postpartum women in KPW $(P<0.05)$, but there was no significant difference in CPW. Also, the score for dietary habits was lower as the hours for watching TV and using mobile phone became longer in postpartum women of both countries, with significant differences in KPW $(P<0.001)$ and CPW $(P<0.05)$. When comparing postpartum women with or without exercise experience, the score for dietary habits in postpartum women with exercise experience was higher in KPW
Table 7. Correlation coefficients between nutritional knowledge, dietary attitude and dietary habits by country

\begin{tabular}{lcccc}
\hline \multicolumn{1}{c}{ Classification } & Nutritional knowledge & Dietary attitude & Dietary habits \\
\hline Nutritional knowledge & 1 & $0.112(0.096)$ & $0.110(0.103)$ \\
Dietary attitude & $0.116(0.086)$ & 1 & $0.054(0.422)$ \\
Dietary habits & $0.205(0.002)^{* * 1)}$ & $0.320(0.000)^{* * *}$ & 1 \\
\hline
\end{tabular}

Correlations for Korean postpartum women below; Chinese postpartum women above

1) $* \star P<0.01,{ }^{\star * \star} P<0.001$

$(P<0.001)$, but there was no significant difference in CPW. The score for dietary habits was higher in postpartum women with nutrition education experience compared to those without experiences in CPW $(P<0.05)$, but no significant difference was found in KPW.

Correlation coefficients between nutritional knowledge, dietary attitude and dietary habits by country

Correlation coefficients between nutritional knowledge, dietary attitude and dietary habits of KPW and CPW are shown in Table 7.

KPW showed a significantly positive correlation between nutritional knowledge and dietary habits $(P<0.01)$, dietary 
attitude and dietary habits $(P<0.001)$. But there was not significant difference in $\mathrm{CPW}$.

\section{DISCUSSION}

Pregnant and lactating women should maintain proper dietary habits and health-related lifestyles for the health of themselves and babies. As active exchanges between Korea and China are increasing recently, it is necessary to provide proper nutrition education considering cultural differences in pregnant women of both countries. Thus, the study was conducted to investigate nutritional knowledge, dietary attitude, dietary habits, nutrition education, and health-related lifestyles of Korean and Chinese postpartum women and to compare all results between two countries.

For physical evaluation, the pre-pregnancy weight of KPW was $55.32 \mathrm{~kg}$, which was slightly lower than the reported weight of $56.5 \mathrm{~kg}$ in 1,047 Korean pregnant women [17]. The prepregnancy weight of CPW was $53.53 \mathrm{~kg}$, which was slightly lower compared to $54.8 \mathrm{~kg}$ reported in the study of pregnant women in Beijing, China [18]. Also, the BMI in KPW was higher compared to CPW, which was similar to the result of a study on Korean and Chinese women in their 20s and 30s showing that the BMl of Korean women was higher than that of Chinese women [19].

For nutritional knowledge, KPW showed higher scores compared to CPW. In the study of college students in Daegu, Korea and Tianjin, China, the score for nutritional knowledge was higher in Korean students (3.9 points) than in Chinese students (3.7 points) [20]. Also, another study reported that the score for nutritional knowledge was higher in Korean college students (17.0 points) compared to Mongolian college students (8.4 points) [21]. Other studies reported that the level of nutritional knowledge was higher in Australian pregnant women as household income and education level were higher and in adults in England as education level became higher $[22,23]$. This was similar to the higher nutritional knowledge in KPW with higher education. However, this was different to the lower nutritional knowledge in CPW with higher household income. Thus it is considered that studies on factors affecting nutritional knowledge are needed to increase the level of nutritional knowledge in pregnant women.

For dietary attitude, KPW showed higher scores than CPW, which was similar to the result of the study on female high school students in Yongin, Korea and Weihai, China showing that the score for dietary attitude was higher in Korean students (2.98 points) compared to Chinese students (2.93 points) [24].

However, for dietary habits, CPW showed more desirable dietary habits compared to KPW. In the study comparing Korean and Chinese female high school students, the score for dietary habits was higher in Chinese students (3.74 points) compared to Korean students (3.12 points) [25]. In the study on Korean and Chinese students, the most important meal of the day was lunch in Korean students while breakfast in Chinese students, and the combination of food groups at each meal was considered more importantly in Chinese students compared to Korean students $[26,27]$. This was similar to the results of the study in which CPW showed higher scores for questions such as 'Do you eat breakfast every day?' and 'Do you consider combination of food groups at each meal?' compared to KPW. From the above results, KPW showed higher level of nutritional knowledge but lower scores for dietary habits compared to CPW. Other studies on Korean and Chinese female high school students and college students reported that Korean students showed higher level of nutritional knowledge but lower scores for dietary habits compared to Chinese students [20,24,26]. This suggests that Korean people have difficulties in practicing acquired knowledge into activities. Thus it is considered helpful to improve dietary habits by providing effective ways to practice nutritional knowledge rather than just transferring the knowledge in preparing nutrition education to Korean pregnant women.

KPW showed more needs for pregnancy-related nutrition education compared to CPW but lacked experiences for actual education. Therefore, it is necessary for KPW to be provided much more chances for nutrition education. For sources of nutrition information, both KPW and CPW replied to obtain most information from Internet or social network services, and then doctor or dietitian. This was similar to the results of the study on the actual state of using Internet and applications in Korean pregnant women, showing that the sources of nutrition information were Internet (35.3\%) and hospital or health center (19.0\%) [28]. Also, a study reported that $88.7 \%$ of Chinese pregnant women obtained pregnancy-related information using Internet from the early stage of pregnancy, mostly information on fetal development and nutrition in pregnancy [29]. Like this, Internet is a major source of nutrition information because pregnant women in the present time are an experienced generation using Internet [30]. Thus, it is considered effective using programs with SNS, Internet broadcasting, and applications for pregnancy-related nutrition education.

For factors affecting dietary habits, the score for dietary habits was higher as the education level was higher in KPW. The education level is a factor affecting not only dietary habits of postpartum women but breastfeeding rate [31]. It is expected that chances for accessing information on dietary habits or breastfeeding are higher as chances for education increase. Dietary habits were not good in both KPW and CPW as the hours of watching TV or using mobile phone were higher. A study on low-income households in the USA reported that too much TV watching during the meal time increased the consumption of unhealthy foods and thus TV watching hours should be reduced [32]. Therefore, postpartum women should be careful not to watch TV or use mobile phone during the meal time. When comparing postpartum women with or without exercise experience, the score for dietary habits was higher in KPW with exercise experience compared to those without experience. Proper exercise after childbirth brings positive effects not only on dietary habits but also on weight control and postpartum depression. In a comparative study of postpartum depression in the exercise group and non-exercise group of Taiwanese postpartum women, the score for postpartum depression was lower in the exercise group compared to the non-exercise group [33]. Regular exercise is recommended to maintain positive physical and psychological conditions after childbirth. When comparing postpartum women with or without the experience of nutrition education for pregnant 
women, the dietary habits were better in CPW with education experience. This was similar to the results in which postpartum women who received professional nutrition education and management during pregnancy showed much more improvements of poor dietary habits [34].

In KPW, nutritional knowledge and dietary attitude had positive correlations with dietary habits. It means that the higher the level of nutritional knowledge, the better the dietary habits, and the better the dietary attitude, the better the dietary habits. In a study of Korean pregnant women, sufficient meal time, regular breakfast eating and various side dishes showed positive correlations, but eating hot, salty, spicy, sweet and instant foods showed negative correlations [35]. Also, a study of Chinese middle and high school students reported that students had healthier dietary lifestyle as the level of nutritional knowledge became higher [36]. As nutritional knowledge and dietary attitude have positive correlations, it is necessary to induce dietary attitude improvement through nutritional knowledge of pregnant women and to provide proper nutrition education to accomplish it.

The limitation of this study is the difficulty of objectification as the overall condition of Korea and China, because it was conducted only in Gyeonggi region of Korea and Jinhua region of China. Despite that, this study is meaningful in which nutritional knowledge, dietary attitude, dietary habits, nutrition education, and health-related lifestyles of Korean and Chinese postpartum women were compared, through which the diversities between Korea and China could be identified.

In summary, KPW showed higher level of nutritional knowledge but lower scores for dietary habits compared to CPW. KPW felt the necessity of pregnancy-related nutrition education much more than CPW but the chances for such education were fewer. KPW had less exercise experience after childbirth compared to CPW; the less the exercise experience, the lower the score for dietary habits. Also, nutritional knowledge and dietary attitude of KPW showed positive correlations with dietary habits. Thus, more pregnancy-related nutrition education should be provided and various and effective nutrition education programs, which not only transfer information but can be used and practiced in the actual life, should be developed. In addition, postpartum women should make some efforts for proper dietary habits, adequate exercise, and health-related lifestyle improvement.

\section{CONFLICT OF INTEREST}

The authors declare no potential conflicts of interests.

\section{ORCID}

Sohyun Kim: https://orcid.org/0000-0002-2060-8772

Heewon L Gray: https://orcid.org/0000-0002-5257-5012

Jia Li: https://orcid.org/0000-0003-4226-0292

Haeryun Park: https://orcid.org/0000-0003-2627-6518

Youngmi Lee: https://orcid.org/0000-0001-9965-0748

Kyunghee Song: https://orcid.org/0000-0001-9549-0716

\section{REFERENCES}

1. Ministry of Health and Welfare, The Korean Nutrition Society. Dietary Reference Intakes for Koreans 2015. Seoul: The Korean Nutrition Society; 2015.

2. Lee JA, Huh YR, Lee Jl, Lim HS. Composition and yield of Korean breast milk and maternal intakes of foods and nutrients. Korean J Nutr 1994;27:795-804.

3. Kim WJ, Ahn HS, Chung EJ. Mineral intakes and serum mineral concentrations of the pregnant and lactating women. Korean J Community Nutr 2005;10:59-69.

4. Duan YF, Jiang S, Wang J, Zhao LY, Pang XH, Bi Y, Yin SA, Yang ZY. Dietary intake status of Chinese lactating women during the first month postpartum in 2013. Zhonghua Yu Fang Yi Xue Za Zhi 2016;50:1043-9.

5. Chung $\mathrm{CW}$, Kim H, Kim H. Body weight changes and lifestyle in women within 1 year after childbirth. Perspect Nurs Sci 2016;13: 88-95.

6. Kim J, Park MS, Lee JW. Nutritional status and eating behavior of lactating women in Daejeon. Korean J Community Nutr 2011;16: 37-50.

7. Statistics Korea. Registered foreigners statistics in South Korea [Internet]. Daejeon: Statistics Korea; 2017 [cited 2018 October 2]. Available from: http://kosis.kr/statHtml/statHtml.do?orgld=101\&tblld =DT_2KAA211\&conn_path=12.

8. Statistics Korea. Foreign residents by the local governments statistics in South Korea [Internet]. Daejeon: Statistics Korea; 2017 [cited 2018 November 22]. Available from: http://kosis.kr/statHtml/statHtml.do? orgld=110\&tblld=TX_11025_A008_A\&conn_path=I2.

9. Song JE, Roh EH, Park SM. Systematic review of quantitative research related to maternal adaptation among women immigrants by marriage in Korea. Korean J Women Health Nurs 2015;21:55-70.

10. Lee JH, Hahn MH, Chung SH, Choi YS, Chang JY, Bae CW, Kim YK, Kim HR. Statistic observation of marriages, births, and children in multi-cultural families and policy perspectives in Korea. Korean $\mathrm{J}$ Perinatol 2012;23:76-86.

11. Jeong GH, Koh HJ, Kim KS, Kim SH, Kim JH, Park HS, Lee YS, Han YR, Kim KW. A survey on health management of during pregnancy, childbirth, and the postpartum of immigrant women in a multi-cultural family. Korean J Women Health Nurs 2009;15:261-9.

12. Kim SH. Pregnancy and childbirth experiences of Chinese marriage immigrant women. J Korean Soc Matern Child Health 2012;16: 170-85.

13. Song JE, Park SM, Roh EH. The postnatal care experiences among first time Chinese immigrant mothers living in Korea. Korean J Women Health Nurs 2016;22:48-60.

14. Bae GM, Cho HS, Lee IS. The review of postpartum care beliefs and practices according to the cultures. J Orient Obstet Gynecol 2009;22:231-42.

15. Hung P. Traditional Chinese customs and practices for the postnatal care of Chinese mothers. Complement Ther Nurs Midwifery 2001;7: 202-6.

16. World Health Organization Western Pacific Region; International Association for the Study of Obesity; International Obesity Task Force. The Asia-Pacific Perspective: Redefining Obesity and Its treatment. Sydney: Health Communications Australia Pty Limited; 2000.

17. Kim SM, Park IH. The effect of pre-pregnancy body mass index, weight gain during pregnancy on birth outcome. Chonnam J Nurs 
Sci 2013;18:108-23.

18. Lai JQ, Teng Y, Dong WL, Yan L, Yin SA. Association of prepregnancy body weight, gestational weight gain and postpartum weight retention among women in Beijing. Zhonghua Yu Fang Yi Xue Za Zhi 2011;45:794-7.

19. Sung M, Sung SK, Chen DS, Gan YJ. Study on body fat and physical characteristics between 20s and 30s Korean and Chinese women. Cloth Res J 2015;15:115-21.

20. Guo SC, Kim HC, Kim MR. A cross-cultural investigation of nutrition knowledge, dietary behaviors, and checking behaviors of food and nutrition labels between Korean and Chinese university students. J East Asian Soc Dietary Life 2015;25:942-51.

21. Erdenebileg Z, Park SH, Chang KJ. Comparison of body image perception, nutrition knowledge, dietary attitudes, and dietary habits between Korean and Mongolian college students. Nutr Res Pract 2018;12:149-59.

22. Bookari K, Yeatman $\mathrm{H}$, Williamson M. Exploring Australian women's level of nutrition knowledge during pregnancy: a cross-sectional study. Int J Womens Health 2016;8:405-19.

23. Parmenter K, Waller J, Wardle J. Demographic variation in nutrition knowledge in England. Health Educ Res 2000;15:163-74.

24. Son S, Ro $Y$, Hyun H, Lee H, Song K. A comparative study on dietary behavior, nutritional knowledge and life stress between Korean and Chinese female high school students. Nutr Res Pract 2014;8:205-12.

25. Ro Y, Hyun W. Comparative study on body shape satisfaction and body weight control between Korean and Chinese female high school students. Nutr Res Pract 2012;6:334-9.

26. Joo EJ, Park ES. Comparison study of dietary behavior, nutrition knowledge, and body weight perception of female high school students in Jeonju, Korea and Jinan, China. Korean J Hum Ecol 2016;25:121-35.
27. Lee J, Gao RR, Kim JH. Acculturation and changes in dietary behavior and anthropometric measures among Chinese international students in South Korea. Nutr Res Pract 2015;9:304-12.

28. Kim SB, Kim JW, Kim MH, Cho YS, Kim SN, Lim HS, Kim SK. A study on consumer's needs for development of diet guide application for pregnant women. Korean J Community Nutr 2013;18:588-98.

29. Gao LL, Larsson M, Luo SY. Internet use by Chinese women seeking pregnancy-related information. Midwifery 2013;29:730-5.

30. Han YH, Kim JH, Lee M, Yoo T, Hyun T. Development of education materials as a card news format for nutrition management of pregnant and lactating women. Korean J Community Nutr 2017;22:248-58.

31. Park JH. The relationship between parental socioeconomic factors and breastfeeding. J Korea Contents Assoc 2014;14:322-30.

32. Horodynski MA, Stommel M, Brophy-Herb HE, Weatherspoon L. Mealtime television viewing and dietary quality in low-income African American and Caucasian mother-toddler dyads. Matern Child Health J 2010;14:548-56.

33. Heh SS, Huang LH, Ho SM, Fu YY, Wang LL. Effectiveness of an exercise support program in reducing the severity of postnatal depression in Taiwanese women. Birth 2008;35:60-5.

34. Lee SJ, Koo KA, Kim DH, Hwang MO, Sohn CY, Park YK, Yang J. Impact of maternal nutrition management during pregnancy on perinatal outcome, in one of the pilot area of Gyeonggi-do province. J Korean Soc Matern Child Health 2017;21:75-85.

35. Kim HW. Development of the pregnancy nutrition knowledge scale and its relationship with eating habits in pregnant women visiting community health center. J Korean Acad Nurs 2009;39:33-43.

36. Song $\mathrm{Y}$, Ahn HJ, Choi JH, Oh SY. Associations of eating habits with obesity and nutrition knowledge for middle and high school adolescents in Shanghai and Heze China. J Korean Soc Food Cult 2014;29:648-58. 